\title{
¿POR QUÉ IMPORTA LA FILOSOFÍA HOY? ACERCA DE LA HISTORICIDAD DE LA FILOSOFÍA
}

\author{
Gustavo Cataldo Sanguinetti \\ Universidad Andrés Bello \\ gcataldo@unab.cl
}

R⿴囗十 En primer lugar, quisiera agradecer muy sinceramente la ocasión que nos brinda el libro de Carlos Peña, Por qué importa la filosofía, para discutir, sin elusiones fáciles, la cuestión acerca de la esencia del saber filosófico. En este sentido, el libro de Carlos Peña tiene la virtud no solamente de desarrollar un perspicaz itinerario de la pregunta por la filosofía-sobre todo en el contexto de la filosofía contemporánea- sino además de hacerlo con toda la radicalidad que implica la pregunta por la estructura originaria de la misma y no solamente por sus efectos o beneficios, por importantes que sean. Sin duda, como bien lo enfatiza Carlos Peña, la radicalidad de la filosofía, tal como es asumida por el pensamiento actual, reside en ya no pensar la relación de la "conciencia" y el mundo desde un sujeto autosuficiente que se autoacredita, sino de una "conciencia" esencialmente extática y volcada al mundo. La expresión heideggeriana in der Welt sein, como estructura existencial del Dasein, expresa precisamente esta unidad originaria entre el hombre y el mundo. La pregunta por qué importa la filosofía alude pues inicialmente, como bien lo precisa Carlos Peña, a la pregunta por esta estructura de la existencia humana por la cual se encuentra originariamente entreverada con el mundo. Si nos interrogamos, entonces, por qué importa la filosofía hoy, en un giro temporal a la pregunta, resulta evidente que uno de los elementos fundamentales de este enlace esencial entre el hombre y el mundo es la propia historicidad de la filosofía. La expresión "filosofía hoy" ciertamente indica una determinación temporal: señala actualidad, vigencia, "eficacia" para influir en el presente. Pero dicha "eficacia" para influir en el presente supone de alguna manera el interrogarnos por la historicidad de la filosofía. Quisiera detenerme brevemente en este aspecto de la pregunta; y ello en la misma medida en que interrogarnos por su importancia supone también responder por la forma de su devenir histórico.

Ciertamente la forma del devenir histórico de la filosofía constituye por sí misma un problema y una objeción para su propia validez. No son pocos los filósofos que han realizado esta objeción: en comparación con la solidez y persistencia de la ciencia, el edificio filosófico más que un edificio parece un campo en ruinas. Los vestigios y las reliquias podrán ser objeto de nostalgia y anhelo romántico, pero difícilmente podrán dar lugar a un saber acreditado. Ya el propio Kant, entre otros muchos, al inicio de la Crítica de la razón pura, consigna este diagnóstico respecto de la metafísica: "Por lo que toca a la unanimidad de lo que sus partidarios afirman, está aún tan lejos de ser un hecho, que más bien es un campo de batalla realmente destinado, al parecer, a ejercitar las fuerzas propias en un combate donde ninguno de los contendientes ha logrado jamás conquistar el más pequeño terreno ni fundar sobre su victoria una posesión duradera" 
(Kant 1978, p. 19). Incluso antes, Descartes, recordémoslo, en su Discurso del Método no vacila en hacer el mismo diagnóstico: "Nada diré de la filosofía sino que al ver que ha sido cultivada por los más excelentes ingenios que han vivido desde hace siglos, y sin embargo, nada hay en ella que no sea objeto de disputa, y, por consiguiente, dudoso, no tenía yo la presunción de acertar mejor que los demás: y considerando cuán diversas pueden ser las opiniones tocantes a una misma materia, sostenidas por gentes doctas, aun cuando no puede ser verdadera más que una, reputaba casi por falso todo lo que no fuera más que verosímil” (Descartes 2011, p. 105).

No resulta pues sorprendente la separación que ha realizado a menudo la misma filosofía respecto de su historia: la historia de la filosofía no es un elemento constitutivo de la filosofía misma, sino, a lo más, un mero acervo de opiniones que, escindido de la verdad, no tiene más certeza que lo puramente verosímil. Sin embargo, existen dos excepciones importantes en lo que se puede denominar el surgimiento de la "conciencia histórica": Hegel y la hermenéutica de Heidegger. Quisiera detenerme brevemente en el primero, sobre todo porque constituye, en cierto sentido, el inicio de este "giro histórico" de la filosofía; giro que reivindica no solamente una peculiar relación de la filosofía con su historia, sino que además, por lo mismo, le confiere una particular vigencia y relación con el presente.

En sus Lecciones sobre historia de la filosofía, Hegel apunta una primera contradicción que debe enfrentar cualquier relación entre la filosofía y la historia: "El primer pensamiento que nos sale al paso cuando de una historia de la filosofía se trata es que este tema encierra, por sí mismo, una contradicción interna" (Hegel 1977, p. 14). Esta contradicción consiste en que por una parte la filosofía aspira a la verdad, a conocer lo inmutable y eterno, lo que existe en y para sí; y por otra parte, la historia narra lo que ha existido en una época para desaparecer en otra. La pregunta para Hegel es pues la relación de la historia con la verdad: cómo incluir en la historia la verdad en cuanto la verdad nunca pasa ni es pasado.

La expresión de esta contradicción no resuelta - de esta separación entre historia y verdad-es para Hegel aquella concepción de la historia de la filosofía como un mero conjunto de opiniones, como una simple doxografía. La contradicción entre filosofía e historia no es, finalmente, sino la antítesis entre epistéme y dóxa. En esta antítesis lo que a menudo subyace no es solamente la idea de que únicamente podemos conocer opiniones y no la verdad, sino además que la convicción, independiente de su fundamento, es la medida suprema de toda validez. Según esta concepción doxográfica, la historia de la filosofía no es más que una galería externa, azarosa y puramente acumulativa de opiniones. En esta historia puramente exterior no hay ciencia ni verdad, ni vida: "la historia de la filosofía -afirma Hegel- no sería otra cosa que un campo de batalla cubierto de cadáveres, un reino no ya de individuos muertos, físicamente caducos, sino también de sistemas refutados, espiritualmente liquidados, cada uno de los cuales mata y entierra al que le precede" (Hegel 1977, p. 22). Hay pues que reiterar la pregunta: ¿cómo integrar intrínsecamente verdad e historia?

La respuesta de Hegel radica en la afirmación de que la historia de la filosofía no es simplemente una colección puramente aditiva de acontecimientos fortuitos, sino 
que hay un movimiento del espíritu pensante, una trayectoria, una cohesión interna y un hilo conductor de su despliegue temporal. A esta trayectoria racional y necesaria Hegel la llama, como es sabido, Entwicklung, desarrollo, evolución, despliegue. En el desarrollo hay que distinguir, afirma Hegel, dos estados: lo que se llama posibilidad (Vermögen), potentia, dúnamisy lo que se denomina realidad (Wirklichkeit), actus, enérgeia. A la posibilidad Hegel la llama ser en sí (Ansichsein) y a la realidad (o efectividad) la llama ser para sí (Fürsichsein). La Entwicklung consiste en el despliegue de todas las potencialidades contenidas en lo en sí hasta llegar a constituirse en una realidad para sí. Así, por ejemplo, en el embrión está contenido en sí la racionalidad, pero solamente cuando la razón deviene razón para sí se puede afirmar que el hombre es un ser realmente racional. Ahora bien, la peculiaridad de la vida del espíritu -a diferencia de la naturaleza- reside en que el desarrollo no consiste en un salir de sí para desdoblarse en dos individuos, sino en un salir de sí que se mantiene en sí: un proceso inmanente donde el salir de sí es simultáneamente mantenerse en sí. De allí que para Hegel la representación adecuada de este desarrollo no sea el de una línea que se expande infinitamente, sino la de un círculo que retorna sobre sí mismo: "Este movimiento encierra, por ser concreto -afirma Hegel- una serie de desarrollos (Entwicklungen) que debemos representarnos, no como una línea recta que se remonta hacia el infinito abstracto, sino como una circunferencia que tiende, como tal, a volver sobre sí misma y que tiene como periferia una multitud de circunferencias que forman, en conjunto, una gran sucesión de desarrollos que vuelven hacia sí mismos" (Hegel 1977, p. 31).

De lo anterior se sigue que para interpretar la idea de "historia de la filosofía" no basta un concepto puramente formal de Entwicklung; es necesario además recurrir al concepto de lo concreto (Konkreten). En efecto, el desarrollo para Hegel no es meramente una actividad formal sin contenido, sino una acción (Tat) cuya actividad (Tätigkeit) consiste precisamente en la unidad esencial del en sí y para sí. Esta unidad de lo mismo y lo otro es lo que le permite a Hegel hablar de la filosofía como "desarrollo de lo concreto" (Entwicklung des Konkreten). Las propias expresiones "abstracto" y "concreto" pueden servir como indicio para entender lo que Hegel propone. La palabra "abstracto", como se sabe, proviene del prefijo latino abs, que indica separación y el verbo trahere, arrastrar o sacar. La palabra "concreto", en cambio, proviene del prefijo cum y el verbo crecere, es decir, crecer junto con, con-crecer. Concreto es pues no lo "separado de", sino lo que "con-crece" en unidad con sus diferencias Valga también un ejemplo que el mismo Hegel pone en sus Lecciones de historia de la filosofía: una flor. Aunque la flor tenga múltiples cualidades -olor, sabor, color, forma- sin embargo, constituye una unidad con sus diversas determinaciones. Por más que el sabor y el perfume de una flor sean cosas distintas, no obstante, constituyen una totalidad unitaria e inclusiva de sus distinciones. La contradicción abstracta es simplemente el resultado de la parcialidad del entendimiento (Verstand) que separa lo que en la realidad está unido. En cambio, únicamente el espíritu (Geist) tiene por objeto no solamente lo concreto, sino además es el desarrollo mismo de lo concreto.

Es este concepto de historia de la filosofía como un "sistema en desarrollo" (System in der Entwicklung), el que le otorga a Hegel la clave para entender la historicidad de la filosofía. De este concepto se desprenden algunas consecuencias importantes. En 
primer lugar, cada filosofía es un momento necesario de la totalidad de su desarrollo: "La historia de la filosofía, considerada en su conjunto, es un proceso necesario y consecuente, racional de suyo y determinado a priori por su idea" (Hegel 1977, p. 40). Atendiendo a la necesidad racional de este proceso, "ninguna filosofía desaparece, sino que todas se conservan afirmativamente en la filosofía como momentos de un todo" (Hegel 1977, p. 40). En este sentido, ninguna filosofía queda definitivamente refutada, ni eliminada ni pertenece simplemente al pasado, sino que queda suprimida-conservada (tollere et conservare), según la conocida ambigüedad de la expresión alemana Aufhebung. En segundo lugar, las diversas filosofías como parte de un "sistema en desarrollo" adquieren su valor y significación -su verdad- solamente como momentos de ese sistema total: únicamente desde el "sitio" peculiar que ocupa cada filosofía es posible juzgar su pretensión veritativa. Pero también de este concepto de desarrollo se deduce la condición "progresiva" de la historia de la filosofía: la filosofía moderna, la más nueva, es más concreta -y, por lo mismo más verdadera- que la más antigua. En definitiva, toda filosofía es epocal: cada filosofía es de $s u$ tiempo porque es expresión de la entera cadena de su desarrollo espiritual y solamente puede dar entera satisfacción a los intereses propios de su tiempo. Por ello la filosofía no puede expresar más que lo que su tiempo permite. Y no es que el tiempo constituya un límite extrínseco a la filosofía, sino que historia y filosofía coinciden: la filosofía no es nada más que una época puesta en conceptos.

De estas consecuencias se deriva, según es evidente, una muy diferente concepción de la "historia de la filosofía". No ya la historia como un devenir puramente externo a la filosofía misma, sino la historia de la filosofía como filosofía sin más: "el estudio de la historia de la filosofía -afirma Hegel- es el estudio de la filosofía misma y no podría ser de otro modo" (Hegel 1977, p. 34). Pero la conclusión que con mayor fuerza se desprende de esta concepción histórica de la filosofía es su relación con el presente: la filosofía por histórica -y no a pesar de ella- es una actividad que se refiere eminentemente al presente. Nada en ella es simplemente pasado: "Por tanto, estos hechos (Taten) no quedan - concluye Hegel - simplemente encerrados en el templo del recuerdo como imágenes del pasado, sino que siguen siendo, hoy, tan presentes, tan vivos, tan actuales, como el momento mismo en que surgieron. Son resultados (Wirkungen) y obras no destruidos y superados (aufgehoben) por otros posteriores, sino en los que debemos vernos presentes todavía nosotros mismos. No se conservan ni en lienzos ni en mármoles, en el papel, en la representación o en la memoria; el elemento en que se perpetúan no es ninguno de estos (es decir, no es ningún elemento perecedero de suyo o que pertenezca al mundo de lo perecedero), sino que es el pensamiento (Denken), el concepto (Begriff), la esencia imperecedera del espíritu, a los que no llegan ni las polillas ni los rateros. Las adquisiciones del pensamiento, en cuanto le han surgido al espíritu, forman parte del ser del espíritu mismo. Estos conocimientos son, por ello mismo, algo más que pura erudición, algo más que el conocimiento de lo muerto, lo enterrado, lo descompuesto; la historia de la filosofía ha de ocuparse de lo que no envejece, de lo presente vivo (gegenwärtig Lebendigen)" (Hegel 1977, p. 42).

La lección de Hegel reside no solamente en haber reivindicado por primera vez la propia historicidad de la filosofía como constitutiva de la filosofía misma, sino también 
en el intento de fundar su propia validez en esa misma historicidad. Se trata sin duda para Hegel -a pesar de su compromiso con una concepción "progresiva" de la mismade salvar la propia vida de la filosofía, vida que por su peculiar historicidad la hace siempre necesaria y vigente. La deuda con Hegel de la hermenéutica contemporánea nos parece por ello mismo evidente. Sin Hegel seguramente la filosofía contemporánea tampoco podría haber radicalizado, como lo ha hecho, su mundanidad vital e histórica.

\section{Referencias bibliográficas}

Descartes, R. (2011), Descartes. Madrid: Gredos.

Hegel, G.W.F. (1977), Lecciones sobre la historia de la filosofía. México: Fondo de Cultura Económica.

(1999), Werke, Band 18. Frankfurt am Main: Suhrkamp.

Kant, E. (1978), Crítica de la razón pura. Madrid: Ediciones Alfaguara. 